\title{
Population structure and environmental niches of Rimicaris shrimps from the Mid-Atlantic Ridge
}

\author{
Pierre Methou ${ }^{1,3}$, Ivan Hernández-Ávila ${ }^{1,4}$, Cécile Cathalot ${ }^{2}$, \\ Marie-Anne Cambon-Bonavita ${ }^{1}$, Florence Pradillon ${ }^{1, *}$
}

\footnotetext{
${ }^{1}$ Univ Brest, Ifremer, CNRS, Unité Biologie et Ecologie des Ecosystèmes marins Profonds, 29280 Plouzané, France

${ }^{2}$ Ifremer, Centre de Bretagne, REM/GM, Laboratoire Cycles Géochimiques et Ressources, 29280 Plouzané, France

${ }^{3}$ Present address: X-STAR, Japan Agency for Marine-Earth Science and Technology (JAMSTEC), Yokosuka 237-0061, Japan

${ }^{4}$ Present address: Facultad de Ciencias Naturales, Universidad Autónoma del Carmen, 14158 Cuidad del Carmen, Mexico
}

\begin{abstract}
Among the endemic and specialized fauna from hydrothermal vents, Rimicaris shrimps constitute one of the most important and emblematic components of these ecosystems. On the MidAtlantic Ridge, 2 species belonging to this genus cooccur: $R$. exoculata and $R$. chacei that differ in their morphology, trophic regime and abundance. $R$. exoculata forms large and dense aggregations on active vent chimney walls in close proximity to vent fluid emissions, whereas $R$. chacei is much less conspicuous, living mostly in scattered groups or solitary further away from the fluids. However, the recent revision of Rimicaris juvenile stages from the MidAtlantic Ridge shows that $R$. chacei abundance would be higher than expected at these early life stages. Here, we describe and compare the population structure of $R$. exoculata and $R$. chacei at the Snake Pit and Trans-Atlantic Geotraverse (TAG) vent fields. We show distinct population demographics between the 2 co-occurring shrimp species with a large post-settlement collapse in $R$. chacei populations suggesting high juvenile mortality for this species. We describe important spatial segregation patterns between the 2 species and their different life stages. Additionally, our results highlight distinct niches for the earliest juvenile stages of both $R$. exoculata and $R$. chacei, compared with all other life stages. Finally, we discuss the potential factors, including predation and competitive interactions, that could explain the differences we observed in the population structure of these 2 species.
\end{abstract}

KEY WORDS: Hydrothermal vents - Life cycle · Population structure $\cdot$ Environmental niches $\cdot$ Juvenile mortality $\cdot$ Rimicaris shrimps

\footnotetext{
${ }^{*}$ Corresponding author: florence.pradillon@ifremer.fr
}

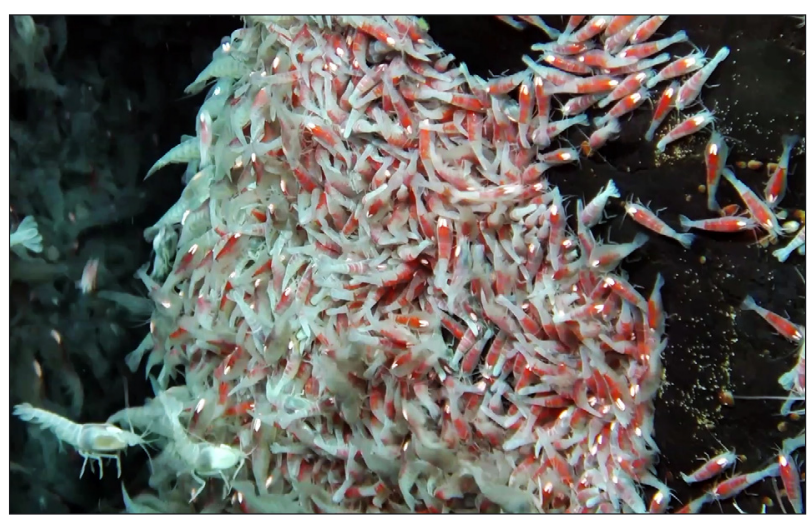

Rimicaris exoculata shrimp adults (light grey color) and juveniles (red color) at Snake Pit vent field (Beehive edifice) on the Mid-Atlantic Ridge.

Photo: BICOSE2 (2018)-Nautile@ifremer

\section{INTRODUCTION}

Fueled by the chemosynthetic energy arising from the mixing between vent fluids and surrounding seawater, hydrothermal vent ecosystems host dense and lush communities of endemic fauna which are organized in distinct species assemblages along steep thermal and chemical gradients. The dynamics of each assemblage depend both on local processes affecting birth and survival rates through local biotic and abiotic interactions, and on broader-scale processes influencing connections between spatially distant assemblages through individual exchanges (e.g. larval dispersal) (Mullineaux et al. 2018). Within this metacommunity framework, species survival over genera-

() The authors 2022. Open Access under Creative Commons by Attribution Licence. Use, distribution and reproduction are unrestricted. Authors and original publication must be credited. 
tions thus depends on the dispersal of larvae, their ability to locate suitable habitats, successfully settle on the bottom and finally enter existing benthic populations or develop into new ones. This implies adaptations at each stage of the life cycle of vent species.

As in other marine benthic ecosystems (Menge 1991), population demographics of species from hydrothermal vents depend on the number of competent larvae reaching the vent site, the probability of success of their settlement and any mortality events occurring between their successive life stages (Kelly \& Metaxas 2008). Therefore, any biotic or abiotic factor affecting one of these 3 steps will likely impact the capacity of individuals to reach sexual maturity and the size of the adult populations. These environmental factors act differentially depending on the life stages considered, as each stage can occupy its own ecological niche and differs in its vulnerability to the different mortality factors (Werner \& Gilliam 1984).

Whereas high juvenile mortality, mostly related to size-selective predation, is often characteristic of the post-settlement phase in shallow-water species (Gosselin \& Qian 1997), a similar generalization has not yet been established in hydrothermal vent ecosystems. This can be attributed to the difficulty of conducting long-term population surveys and temporal observations along appropriate timescales in such remote places. Settlement and recruitment patterns of these species have thus mostly been inferred from cohort monitoring. According to these studies, populations of some vent species such as Bathymodiolus azoricus mussels or some gastropods are largely dominated by small-sized individuals (Comtet \& Desbruyères 1998, Kelly \& Metaxas 2008), implying either an important juvenile mortality or large variations between the different recruitment events. Conversely, a limited number of juveniles has been reported for several other taxa, including alvinellid polychaetes and many peltospirid or lepetodrilid gastropods (Zal et al. 1995, Faure et al. 2007, Matabos \& Thiebaut 2010, Marticorena et al. 2020), suggesting frequent arrival of larvae at the vent field followed by a fast growth rate and an accumulation within the adult populations. Still, spatial or temporal limitation in sampling could also bias our understanding of post-settlement processes in these populations, as different life stages sometimes inhabit different parts of the field. Important spatial zonation between juveniles and adults has been reported for instance in Kiwa tyleri crabs, in which adults aggregate near the fluid exits while juveniles remain restricted to the periphery of the field (Marsh et al. 2015). Similarly, segregation by size was observed along a thermal gradient in $B$. azoricus mussels, with juveniles and small mussels preferentially found in areas with lower temperatures (Husson et al. 2017).

Rimicaris shrimps are important components of hydrothermal vent ecosystems, as they constitute some of the most visually dominant megafauna in several regions such as in the Central Indian Ridge (Watanabe \& Beedessee 2015), the Mid-Cayman Rise (Plouviez et al. 2015) or the Mid-Atlantic Ridge (MAR) (Zbinden \& Cambon-Bonavita 2020). In the northern part of the MAR, 2 species of this genus cooccur: $R$. exoculata, which forms large aggregations close to vent fluid emissions, with densities of several thousands of individuals per $\mathrm{m}^{2}$, and R. chacei, presumed to be less abundant than its congener (several tens to hundreds of individuals per $\mathrm{m}^{2}$ ), as individuals are less conspicuous within the vent fields (Segonzac et al. 1993).

It is assumed that population demography of congeneric species should be comparable especially when they evolve in similar habitat conditions (Münzbergová 2013). However, observations of contrasting population sizes and distribution patterns in many biologically similar congeners suggest that distinct population dynamics can exist even in cases of syntopy when species jointly occupy the same habitat at the same time (Münzbergová 2013, Jones \& Ricciardi 2014, Bouchemousse et al. 2017). A stable co-occurrence at a small spatial scale of closely related species usually presupposes some differentiation in resource use as well as mechanisms that prevent interbreeding (Beermann \& Franke 2012). When congeners display similar biological traits and ecological niches, competitive processes are expected to be intensified (Franke et al. 2007, Rius et al. 2009), although they do not necessarily constitute a major driver of their population dynamics (Bouchemousse et al. 2017). The 2 Rimicaris species differ by their trophic regime, with $R$. exoculata being highly dependent on the dense and diversified chemosynthetic episymbiotic communities hosted in their enlarged cephalothorax (Gebruk et al. 2000, Ponsard et al. 2013, Zbinden \& Cambon-Bonavita 2020) and $R$. chacei relying on symbiotrophy, bacterivory and scavenging (Gebruk et al. 2000, Apremont et al. 2018). This mixotrophic regime of $R$. chacei has been hypothesized to result from the competition for space with $R$. exoculata that would maintain $R$. chacei at a distance from vent fluids essential for fueling their symbionts (Apremont et al. 2018). 
Zonation patterns between $R$. exoculata life stages have been reported in different studies (Segonzac et al. 1993, Shank et al. 1998, Gebruk et al. 2010) which highlighted the existence of patches of red juveniles adjacent to the dense aggregations of adults in several MAR vent fields. More recently, spatial segregation between males, found at the periphery away from the fluid mixing zones, and females, mainly occurring within the dense aggregations on active chimney walls, have also been observed (HernándezÁvila et al. preprint: https://doi.org/10.1101/2021. 06.27.450066). In addition, dense aggregations of small juveniles were also collected close to peripheral and diffuse fluid emissions arising from cracks at the Trans-Atlantic Geotraverse (TAG) vent field (Methou et al. 2020, Hernández-Ávila et al. preprint). Surprisingly, these individuals were revealed to be juvenile stages of $R$. chacei, indicating a misidentification in the previous species affiliation of these life stages (Methou et al. 2020, Hernández-Ávila et al. preprint). Such a large abundance of $R$. chacei early life stages was unexpected considering the low abundance of the adults, and implied for $R$. chacei either a low postsettlement survival or a larger adult population than previously stated, or both. Therefore, a full characterization of the population structures of $R$. exoculata and $R$. chacei is required to properly assess the demography of each species and whether the differences in the relative abundance of life stages could be related to their different trophic strategies or to other external factors such as predation, or physiological stress arising from their environment.

In this study, we used the case of $R$. exoculata and $R$. chacei to explore mechanisms allowing the coexistence of populations of 2 congeneric species within vent habitats, where trophic resources are abundant but very restricted spatially. We hypothesized that different demographic patterns, as well as niche partitioning may both be involved in the co-existence of these vent shrimps. To test these hypotheses, we conducted a detailed analysis of population structures of each species comparing their global size-frequency distributions within 2 vent fields along the northern MAR, namely TAG and Snake Pit. We also examined the distribution of sexes and life stages within visually distinct types of shrimp assemblages for which we also obtained temperature as well as chemical data. This allows us to characterize the realized environmental niches of each species through juvenile development to the adult stage, and discuss how biotic and abiotic factors may influence their demography, ultimately providing insights into mechanisms potentially involved in their co-existence.

\section{MATERIALS AND METHODS}

\subsection{Field sampling}

Rimicaris shrimps were collected on board the RV 'Pourquoi pas?' during the BICOSE 2 cruise (http:// dx.doi.org/10.17600/18000004) between 26 January and 10 March 2018 at the TAG $\left(26^{\circ} 08.2^{\prime} \mathrm{N}\right.$, $44^{\circ} 49.5^{\prime} \mathrm{W}, 3620 \mathrm{~m}$ depth) and the Snake Pit $\left(23^{\circ} 22.1^{\prime} \mathrm{N}, 44^{\circ} 57.1^{\prime} \mathrm{W}, 3470 \mathrm{~m}\right.$ depth) hydrothermal vent fields using the suction sampler of the HOV 'Nautile'. Samples were collected all over the active venting areas at the TAG vent field and on the 3 active edifices of Snake Pit: the Beehive, the Moose and the Nail (see Fig. S1 in the Supplement at www.int-res.com/articles/suppl/m684p001_supp/). In total, we collected $3919 R$. exoculata shrimps (1533 from TAG and 2386 from Snake Pit) and 1201 R. chacei shrimps (886 from TAG and 315 from Snake Pit).

Spatially discrete samples were targeted to explore the fine-scale variations in the distribution of populations of each species, from 10s of centimeters for high-density areas to several meters in sparsely populated areas, with 13 different spatial samples at TAG and 17 at Snake Pit (Table S1). These samples were classified according to the type of vent fluid emissions and their proximity to them. During the dives, each sample was kept separate using the different chambers of the suction sampler carousel and the closeable bioboxes of the HOV 'Nautile'. All shrimps were stored in $80 \%$ EtOH. For 20 of the sampling points, temperature measurements were carried out prior to sampling shrimps, moving the $\mathrm{HOV}$ temperature probe across several points $\left(0.1^{\circ} \mathrm{C}\right.$ precision for a temperature below $50^{\circ} \mathrm{C}$ ) within the targeted sampling area, for 3 to 6 min 45 s with a sampling frequency of $1 \mathrm{~Hz}$.

Additionally, a more precise environmental characterization of the vent fluid chemistry was obtained for 14 of these sampling points with $\mathrm{pH}$, iron $\left(\mathrm{Fe}^{2+}\right.$ and total iron, $\mathrm{Fe}_{\text {tot }}$ ) and $\mathrm{H}_{2} \mathrm{~S}$ concentration measurements. Water samples were collected with the PEPITO sampler implemented on the HOV 'Nautile' (Sarradin et al. 2008) and equipped with blood bags (Terumo ${ }^{\circledR}$ ). The suction inlet was coupled to the HOV temperature probe. Prior to use, all equipment used for sampling was rigorously washed 3 times with diluted hydrochloric acid ( $\mathrm{pH} \mathrm{2;} \mathrm{Suprapur,} \mathrm{Merck)} \mathrm{and} \mathrm{then}$ thoroughly rinsed with ultrapure water (Milli-Q element system). Immediately after the recovery of the HOV, samples were processed in the chemical lab onboard (clean lab, P 100000 ; ISO8), and pH was measured on a subsample using a Metrohm $\mathrm{pH}$ 
meter. Measurements were carried out after calibration of the $\mathrm{pH}$ meter with NBS buffers ( $\mathrm{pH} \mathrm{4,7}$ and 10) at $25^{\circ} \mathrm{C}$. Total iron $\left(\mathrm{Fe}_{\text {tot }}\right)$ concentration was determined onboard on water samples taken by PEPITO using the Ferrozine spectrophotometric method (Stookey 1970). Free inorganic sulfides $\left(\Sigma \mathrm{S}=\mathrm{HS}^{-}+\right.$ $\mathrm{S}^{2-}+\mathrm{H}_{2} \mathrm{~S}$; Le Bris et al. 2000) were also determined onboard on recovered water samples using the spectrophotometric method of Cline (1969).

In addition to the PEPITO sampling, total dissolvable $\mathrm{Fe}^{2+}$ was measured in situ using a chemical miniaturized analyzer (CHEMINI; Vuillemin et al. 2009). The in situ measurement was based on flow injection analysis with a colorimetric detection (methylene blue method). A calibration of the analyzer was performed in situ at the beginning and at the end of each HOV dive using Fe(II) stock solutions. Hydrothermal samples were pumped without any filtration, and the signal acquisition ( $3 \mathrm{~min})$ was initiated at the same time as the water sampling since the same inlet was used for both PEPITO and CHEMINI. Finally, the in situ concentration of dissolved oxygen was monitored during each sampling using an optode (Aanderaa).

\subsection{Life stage identifications and measurements}

For each individual, carapace length (CL) was determined to the nearest $0.1 \mathrm{~mm}$ by Vernier calipers from the rear of the eye socket to the rear of the carapace in the mid-dorsal line. Each shrimp was identified and sorted according to its life stage and sex. Sex was identified in adults by the occurrence of the appendix masculina on the second pleopod in males, and by the shape of the endopod of the first pleopod (Komai \& Segonzac 2008). Since these sexual characters appear only at the adult stage, sex of juvenile/ subadult specimens could not be determined.

Juvenile stages A and B of $R$. exoculata and juvenile stage A of $R$. chacei were identified according to Methou et al. (2020). Because pleopod morphologies are identical between subadults and small females, the distinction between them was made according to the onset of sexual differentiation (OSD) size defined previously for $R$. exoculata and $R$. chacei, respectively, for a CL of 10 and $5.98 \mathrm{~mm}$, respectively (Methou et al. 2020, Hernández-Ávila et al. preprint: https://doi.org/10.1101/2021.06.27.450066). All individuals without male characteristics were sorted as females if their size exceeded OSD, whereas individuals with a smaller size than OSD were sorted as subadults. Subadults and juvenile stages were some- times considered together as immature individuals in the analyses.

The dataset compiling size, sex and life stage identifications of each shrimp individual is available in the SEANOE database (https://doi.org/10.17882/84192).

\subsection{Statistical analysis of population structure}

Rimicaris shrimps were grouped first by species and then by life stage for each vent field. Visual examination of our dataset and Shapiro-Wilk normality tests revealed that the size distributions of the shrimps collected during the BICOSE 2 expedition did not follow a Gaussian distribution. Therefore, non-parametric tests were used for intergroup comparisons, using a Mann-Whitney test to compare differences in size between vent fields (Snake Pit vs. TAG), species (R. exoculata vs. $R$. chacei) or sex (females vs. males). Size frequency distributions between groups were compared with KolmogorovSmirnov 2-sample goodness of fit tests. Significant variations in the proportions of the 2 Rimicaris species or in proportions of immature to adult individuals for each species were tested using a $\chi^{2}$ test with a Yates correction for $1 \mathrm{df}$. Frequencies of males and females in samples were tested for significant variation from a 1:1 sex ratio using a $\chi^{2}$ test with a Yates correction for $1 \mathrm{df}$ (detailed $\mathrm{p}$-values for these tests are given in Table S2). The different spatial samples were grouped by $k$-means hierarchal clustering based on a Euclidean distance matrix and displayed with a heatmap. The optimal number of groups was determined both visually and statistically using the gap statistic method (Tibshirani et al. 2001). All tests were performed using R version 3.6.1 (R Core Team 2020).

\subsection{Cohort analysis of the population structure}

Histograms of the size frequency distributions were analyzed as mixtures of normal distributions for samples containing at least 40 individuals. Size-frequency histograms were plotted using a $1 \mathrm{~mm}$ size class interval. This interval was chosen to meet the following criteria described by Jollivet et al. (2000): (1) most size classes have at least 5 individuals each, (2) adjacent empty size classes have been minimized, and (3) the interval is clearly larger than the estimated error rate in measurements. We determined the overlapping component distribution that gives the best fit to the histogram with the 'mixdist' R package (Macdonald \& Du 2012). Our modal decomposi- 
tions were considered as valid according to the test from the 'mixdist' package, which is based on the $\chi^{2}$ approximation to the likelihood ratio statistic. This allowed the identification of gamma components and their parameters, i.e. mean, sigma and estimated proportion, each corresponding respectively to the mean CL size, the standard deviation of the CL size and the proportion of a defined cohort.

\subsection{Thermal and environmental niches of each species, sex and life stage}

Four temperature descriptors were calculated for each of the 20 population samples where temperature was measured: the mean (Avg.T), the minimum (Min.T), the maximum (Max.T) and the standard deviation (Std.T) (Table S3). Four additional environmental measures $\left(\mathrm{pH}, \mathrm{H}_{2} \mathrm{~S}, \mathrm{Fe}^{2+}\right.$ and $\mathrm{Fe}_{\text {tot }}$ concentrations) were used for 14 of these samples (Table S3) for a second, more refined, niche analysis. Values below the detection limit of the measurement devices were considered as null for the niche analysis. Pearson's correlations were used to select non-redundant variables.

The niches of males, females, subadults and juveniles of each shrimp species were examined similarly to the study of thermal niches of species encountered in Bathymodiolus azoricus mussel beds at the Lucky Strike vent field (Husson et al. 2017). The niche of a set of specimens (i.e. males, females, subadults or juvenile stages) was studied using the outlier mean index (OMI) created by Dolédec et al. (2000), and computed using the 'niche' function in the R package 'ade4' (Dray \& Dufour 2007). On a PCA of environmental parameters, sampling points corresponding to the different population samples collected are weighted by the number of specimens. The center of gravity of each of these weighted points is the average position of a group of individuals, defined here by species and life stage or sex, in the scatterplot defined by the PCA, i.e. the average environmental conditions in which this group thrives. Different indexes are given by the OMI analysis, including the OMI index, also called 'marginality'. A permutation test is used to check the significance of this index, indicating if species marginality is significantly higher than expected by chance. If this test is not significant, this means that the species distribution is independent of the environmental conditions. The OMI analysis also gives a measure of the niche breadth: the tolerance index (Tol), which corresponds to the variance around the centroid. Associated with tolerance (Tol), the residual tolerance (RTol) index, defined as the part of the variance that is not explained by the environmental variables used in the PCA, indicates whether the chosen variables are suitable for the niche analysis. These 3 indexes (OMI, Tol and RTol) constitute the total inertia of the niche, and each can be expressed as a percentage of this inertia. At the same time, OMI analysis also identifies the variables that best differentiate the environmental niches of the studied group of individuals.

\section{RESULTS}

\subsection{Population structures of Rimicaris shrimps at TAG and Snake Pit in February-March 2018}

At each vent field, overall size distributions of the 2 Rimicaris species were different from each other with significantly distinct size-frequency distributions both at TAG (Kolmogorov-Smirnov 2-sample test, $D=$ $0.949, \mathrm{p}<0.001)$ and at Snake Pit vent fields $(D=$ $0.545, \mathrm{p}<0.001)$. Unlike $R$. exoculata, $R$. chacei size distribution was indeed skewed towards the smaller sizes, corresponding to the juvenile and subadult life stages (Fig. 1). This resulted in a significantly higher proportion of immature individuals for $R$. chacei compared with $R$. exoculata, both at TAG $(R$. chacei: $91.9 \%, R$. exoculata: $23.8 \% ; \chi^{2}=1036.4, \mathrm{p}<0.001$; Table 1) and at Snake Pit ( $R$. chacei: $52.1 \%, R$. exoculata: $32.6 \%$; $\chi^{2}=45.74, \mathrm{p}<0.001$; Table 1 ). Immature individuals represented a significantly higher proportion of the whole $R$. chacei population at TAG compared with Snake Pit $\left(\chi^{2}=240.3, \mathrm{p}<0.001\right)$, whereas immature individuals were significantly more represented in Snake Pit populations of $R$. exoculata compared with TAG $\left(\chi^{2}=34.2, \mathrm{p}<0.001\right)$. Nonetheless, a similar proportion of $R$. chacei stage A juveniles were observed in the populations of both vent fields (TAG: $41.2 \%$, Snake Pit: $38.1 \% ; \chi^{2}=0.79, p=$ $0.373)$. However, $R$. exoculata stage A juveniles were still in lower proportions at the TAG vent field (TAG: $3.7 \%$, Snake Pit: $13.9 \% ; \chi^{2}=108.03, p<0.001$ ).

Overall, larger sizes were observed for $R$. exoculata compared with $R$. chacei at any life stage, either for adults, subadults or juvenile stages (Table S4; MannWhitney test, $\mathrm{p}<0.001$, all cases). The largest recorded adults of the 2 species were nonetheless of similar size at TAG (20.1 and $20.5 \mathrm{~mm}$ CL respectively for $R$. exoculata and $R$. chacei) but were bigger for $R$. exoculata at Snake Pit (24.4 and $21.1 \mathrm{~mm} \mathrm{CL}$ respectively for $R$. exoculata and $R$. chacei). Males of $R$. exoculata exhibited significantly larger average sizes than females in both vent fields (TAG: $W=$ 24 460, p < 0.001; Snake Pit: $W=80537, \mathrm{p}<0.001$ ). 

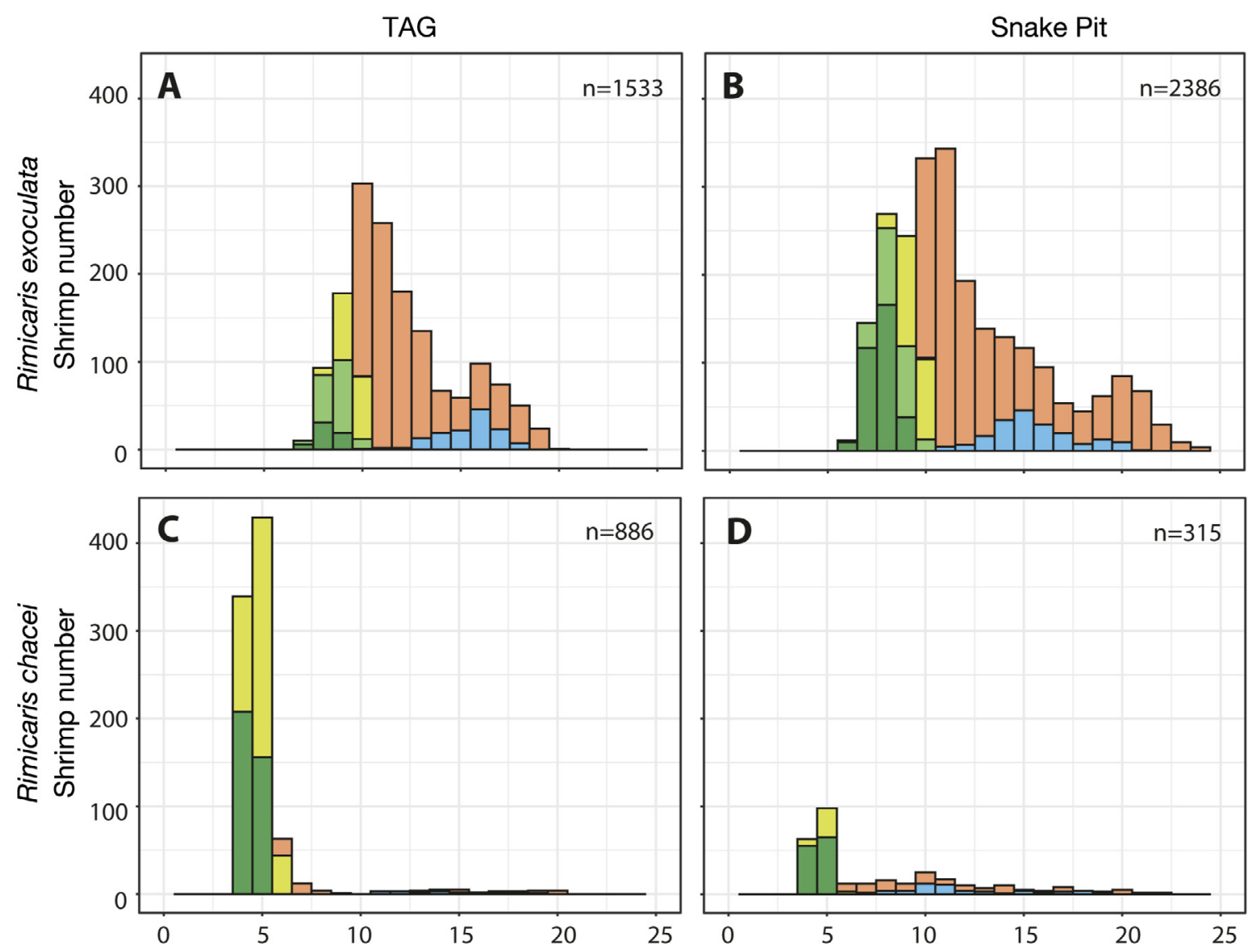

Carapace length $(\mathrm{mm})$

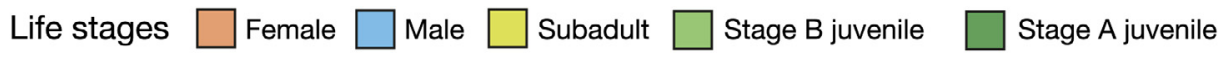

Fig. 1. Size-frequency distribution of Rimicaris exoculata and $R$. chacei from 2 vents fields (Trans-Atlantic Geotraverse [TAG] and Snake Pit), denoting life stages and sexes: (A) $R$. exoculata from TAG, (B) $R$. exoculata from Snake Pit, (C) $R$. chacei from TAG, (D) R. chacei from Snake Pit

However, the largest recorded $R$. exoculata adults were females both at TAG and at Snake Pit (20.1 and $24.4 \mathrm{~mm} \mathrm{CL}$, respectively). In $R$. chacei, the average size of males and females was not significantly different at Snake Pit $(W=2180, \mathrm{p}=0.065)$, and males were slightly larger than females on average at TAG $(W=249.5, \mathrm{p}=0.001)$. As with $R$. exoculata, the largest recorded $R$. chacei adults were females at both vent fields (20.5 and $21.8 \mathrm{~mm} \mathrm{CL}$, respectively).

At each vent field, MIX modal decomposition detected 4 cohorts in the populations of $R$. exoculata and 3 cohorts in the populations of R. chacei (Fig. S2). In $R$. exoculata, the second and third cohorts had the highest proportions of individuals, roughly two-

Table 1. Sample and population data of Rimicaris exoculata and $R$. chacei from the Trans-Atlantic Geotraverse (TAG) and Snake Pit vent fields, Mid-Atlantic Ridge. Significance levels: ${ }^{* *} \mathrm{p}<0.01,{ }^{* * *} \mathrm{p}<0.001 ;-$ : not applicable

\begin{tabular}{|c|c|c|c|c|c|c|c|c|c|c|c|c|}
\hline Species & $\begin{array}{l}\text { Vent } \\
\text { field }\end{array}$ & $\begin{array}{c}\text { Total } \\
\text { specimens }\end{array}$ & Total & $\begin{array}{c}\text { Adults } \\
\text { Female } \\
\text { (TF) }\end{array}$ & $\begin{array}{l}\overline{\text { Male }} \\
(\mathrm{TM})\end{array}$ & Total & $\begin{array}{l}\text { Imm } \\
\text { Subadult }\end{array}$ & $\begin{array}{c}\text { Iatures } \\
\text { Juvenile } \\
\text { B }\end{array}$ & $\begin{array}{c}\text { Juvenile } \\
\text { A }\end{array}$ & TM:TF & \multicolumn{2}{|c|}{$\begin{array}{l}\text { Sex ratio } \\
\chi^{2} \text { Significance } \\
(1 \mathrm{df})\end{array}$} \\
\hline Rimicaris & TAG & 1533 & 1168 & 1033 & 135 & 365 & 155 & 153 & 57 & $0.13: 1$ & 690.41 & $* * *$ \\
\hline exoculata & Snake Pit & 2386 & 1609 & 1415 & 194 & 777 & 232 & 212 & 333 & $0.14: 1$ & 926.56 & $* * *$ \\
\hline Rimicaris & TAG & 884 & 72 & 53 & 19 & 812 & 448 & - & 364 & $0.36: 1$ & 16.06 & $* * *$ \\
\hline chacei & Snake Pit & 315 & 151 & 95 & 56 & 164 & 44 & - & 120 & $0.59: 1$ & 10.07 & $* *$ \\
\hline
\end{tabular}


thirds of the populations, both at TAG and at Snake Pit (Table 2). These 2 cohorts mostly included adults with some immature stages below the OSD in the second cohort. The first cohort only comprised immature individuals and represented at most $1 / 5$ of the total population. The fourth cohort comprised the larger adults, and represented at most $1 / 5$ of the total population. In $R$. chacei, however, the first cohort that included mostly immature individuals comprised half of the population at Snake Pit and up to $92.5 \%$ of the population at TAG. The second cohort of $R$. chacei comprised small adults mostly, with proportions varying between 3 and nearly $40 \%$ of the whole population. The third cohort comprised large adults, representing only $4-12 \%$ of the total population (Table 2 ).

Populations of the 2 Rimicaris species also differed by their sex ratio. As reported for 2014 (HernándezÁvila et al. preprint: https://doi.org/10.1101/2021. 06.27.450066), sex ratios of $R$. exoculata collected in 2018 from TAG and Snake Pit were strongly biased towards females at both vent fields (TAG: $\chi^{2}=690.41$, $\mathrm{p}<0.001$; Snake Pit: $\chi^{2}=926.56, \mathrm{p}<0.001$; Table 1). Similarly, sex ratios of the $R$. chacei collected at these vent fields deviated significantly from 1:1 (TAG: $\chi^{2}=$ 16.06, $\mathrm{p}<0.05$.; Snake Pit: $\chi^{2}=10.07, \mathrm{p}<0.001$; Table 1). However, this deviation from a 1:1 sex ratio was less marked in $R$. chacei populations compared with $R$. exoculata, with a much larger proportion of males among adult individuals at TAG $(R$. chacei: $26.4 \%, R$. exoculata: $\left.11.6 \% ; \chi^{2}=12.38, \mathrm{p}<0.001\right)$ and at Snake Pit ( $R$. chacei: $37.1 \%, R$. exoculata: $\left.12.1 \% ; \chi^{2}=68.92, \mathrm{p}<0.001\right)$. For each species, sex ratios did not vary significantly between populations of the 2 vent fields $\left(R\right.$. chacei: $\chi^{2}=0.12, \mathrm{p}=0.732 ; R$. exoculata: $\chi^{2}=2.04, \mathrm{p}=0.153$ ).

\subsection{Spatial variation in the population structure of Rimicaris shrimps from TAG and Snake Pit}

Our 30 samples were assigned to 6 visually distinct types of assemblages (Fig. 2) according to the domi- nant Rimicaris life stage/species/sex and the proximity of the sampled assemblage to the hydrothermal activity. More specifically, these assemblages were classified as close to active emissions for those adjacent to black smokers, close to diffuse emissions for those in a close proximity to transparent shimmering flows, or in inactive areas when no vent fluid could be detected visually in their surroundings. Six clusters were also determined statistically to be the optimal number of clusters for our population dataset using the gap statistic method (Fig. 3).

The most visually dominating assemblage type was the dense aggregations observed close to the active vent fluid emissions (Fig. 2A; Fig. S3). These assemblages comprised almost exclusively $R$. exoculata, with $R$. chacei sometimes also present but in very low proportions $(R$. chacei: $0.9-10.4 \%$ of all Rimicaris shrimps; $\left.\chi^{2}=93.5-714.1, \mathrm{p}<0.001\right)$. Most of the dense aggregations were dominated by adults of $R$. exoculata, with a larger proportion of adults in all samples (67.4-94.2\% of all $R$. exoculata of a given sample, $\left.\mathrm{n}=13 ; \chi^{2}=47.1-501.1, \mathrm{p}<0.001\right)$, except in one from Snake Pit (The Nail edifice) that exhibited similar proportions of adults and immature individuals $\left(\chi^{2}=0.46, p=0.49\right)$. The majority of immatures from this population sample were at an advanced juvenile stage (i.e. subadults or stage B juveniles), with early juveniles only representing $2.6 \%$ of all the $R$. exoculata individuals. Large variations were observed in the proportions of immature stages between the different samples from dense aggregations from 5.8 to $32.6 \%$ of all the $R$. exoculata individuals. For nearly all of the dense aggregation samples (13 out of 14 samples), sex ratio of $R$. exoculata strongly deviated from $1: 1\left(\chi^{2}=31.2-311, \mathrm{p}<\right.$ 0.001 ), with a large bias toward females. One exception was found in a dense aggregation sample from TAG exhibiting an equilibrated sex ratio for $R$. exoculata $\left(\chi^{2}=0.69, \mathrm{p}>0.05\right)$.

At the periphery of the dense aggregations, in parts less impacted by the turbulent mixing between hydrothermal fluid and seawater, or where fluid exits

Table 2. Cohort analysis with proportions (\%), mean and SD of the modal components estimated from the size-frequency distributions of Rimicaris exoculata and $R$. chacei collected from TAG and Snake Pit vent fields. -: not applicable

\begin{tabular}{|c|c|c|c|c|c|c|c|c|c|c|c|c|c|}
\hline \multirow{2}{*}{ Species } & \multirow[t]{2}{*}{ Vent field } & \multicolumn{3}{|c|}{ Cohort $1-$} & \multicolumn{3}{|c|}{ Cohort $2-$} & \multicolumn{3}{|c|}{- Cohort $3-$} & \multicolumn{3}{|c|}{ Cohort 4} \\
\hline & & $\%$ & Mean & $\mathrm{SD}$ & $\%$ & Mean & $\mathrm{SD}$ & $\%$ & Mean & $\mathrm{SD}$ & $\%$ & Mean & SD \\
\hline \multirow[t]{2}{*}{ Rimicaris exoculata } & TAG & 14.5 & 8.6 & 0.6 & 25.2 & 10.3 & 0.6 & 39.6 & 11.9 & 1.3 & 20.7 & 16.5 & 1.3 \\
\hline & Snake Pit & 21.7 & 7.9 & 0.7 & 33.5 & 10.5 & 0.9 & 33.6 & 13.7 & 2.4 & 11.2 & 20.4 & 1.4 \\
\hline \multirow[t]{2}{*}{ Rimicaris chacei } & TAG & 92.5 & 4.7 & 0.4 & 3.3 & 6.8 & 0.3 & 4.2 & 15.3 & 3.2 & - & - & - \\
\hline & Snake Pit & 48.9 & 4.6 & 0.3 & 39.4 & 9.4 & 2.5 & 11.7 & 17.4 & 2.4 & - & - & - \\
\hline
\end{tabular}


were dampened, a second type of assemblage was observed at Snake Pit (The Beehive), also largely dominated by $R$. exoculata (Fig. 2B; Fig. S4A). Unlike dense aggregations, these 2 population samples exhibited large proportions of immatures $\left(\chi^{2}=202.2\right.$, $\mathrm{p}<0.001 ; 231.2, \mathrm{p}<0.001)$ representing 90.4 and $91.3 \%$ of all $R$. exoculata individuals collected there. These assemblages were considered nurseries of $R$.
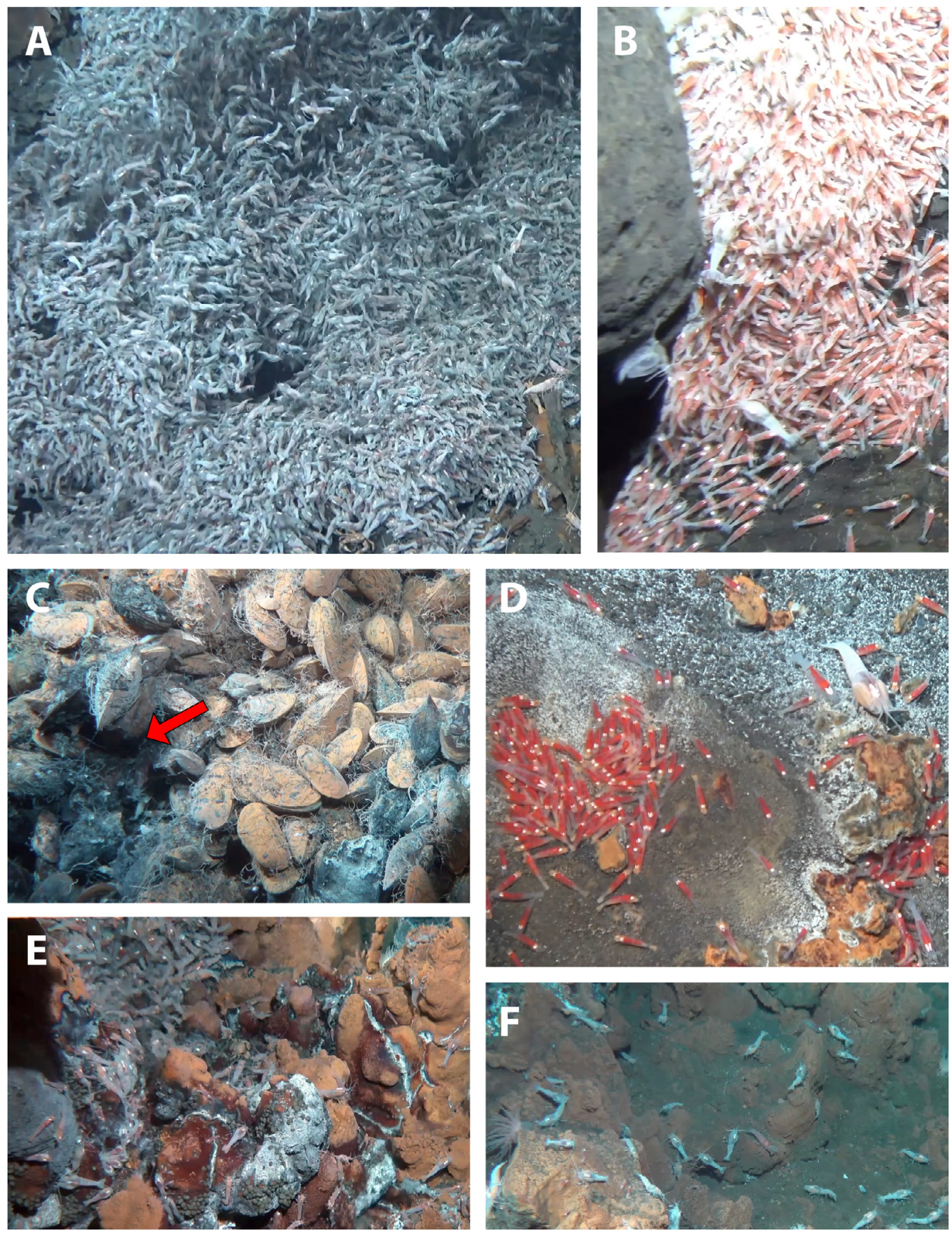

Fig. 2. Overview of the different Rimicaris assemblage types from TAG and Snake Pit vent fields. (A) Dense aggregation of $R$. exoculata adults observed near vent fluid exits at TAG. (B) Nursery of $R$. exoculata adjacent to the dense adult aggregation on the flank of chimneys at Snake Pit. (C) Hidden aggregation of $R$. chacei (red arrow) observed behind a mussel bed at Snake Pit. (D) $R$. chacei nursery associated with low temperature diffusions at TAG. (E) Low-density alvinocaridid assemblage at the periphery of a dense aggregation of $R$. exoculata at TAG. (F) Scattered Rimicaris individuals, in areas away from any visible vent fluid emissions at TAG 


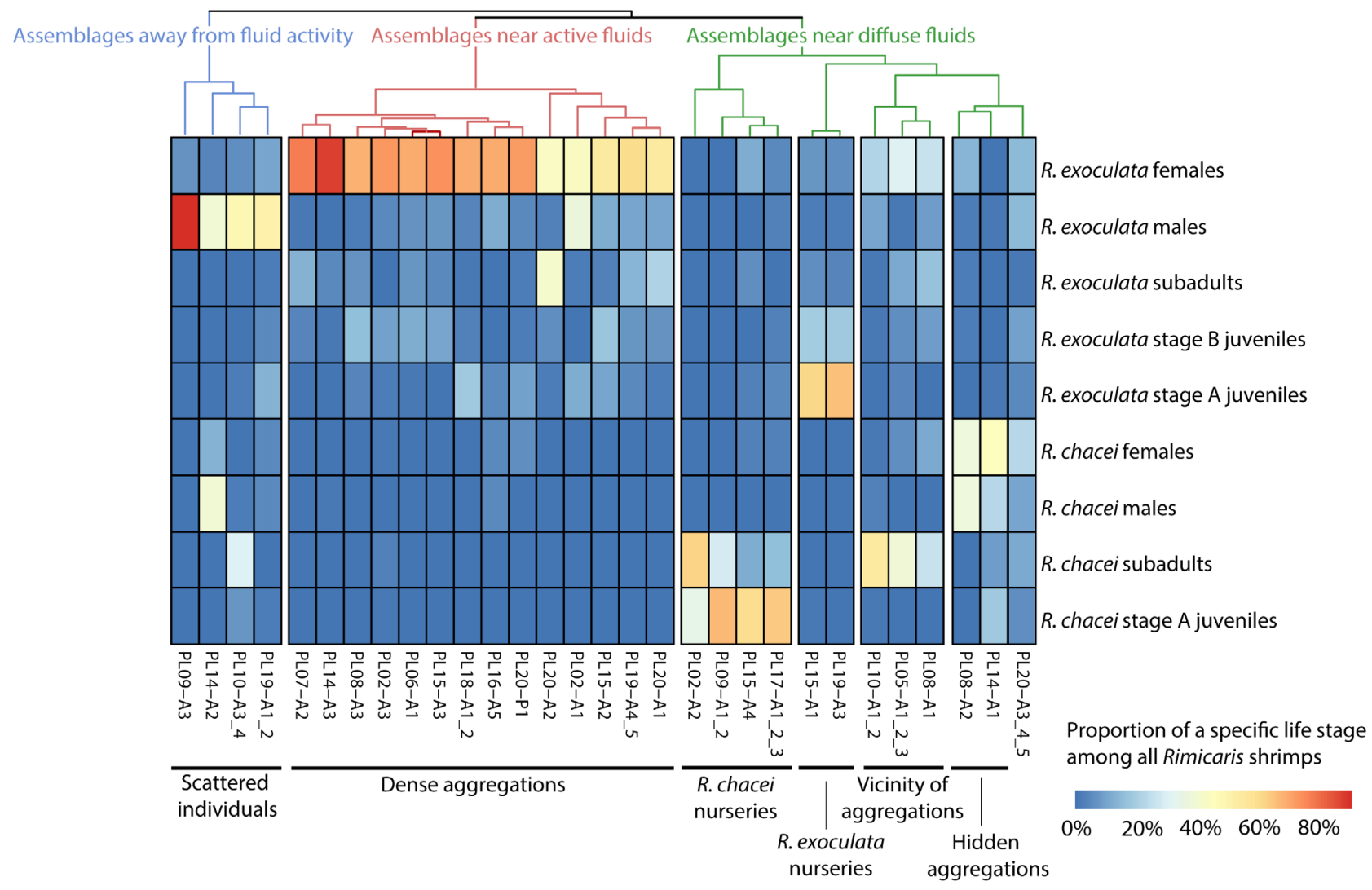

Fig. 3. Heat map displaying hierarchical clustering of the different samples collected in this study, according to their composition (in terms of species, sexes and life stages). Each column of the heat map corresponds to one sample with its ID provided below

exoculata. Most of these immature individuals were at an early juvenile stage, with stage A juveniles representing 70.4 and $74.5 \%$ of all the immature individuals. In addition, the sex ratio of the few $R$. exoculata adults from these assemblages did not significantly deviate from $1: 1\left(\chi^{2}=3.2, \mathrm{p}=0.07\right)$ or was only slightly biased towards females $\left(\chi^{2}=5.4, \mathrm{p}=\right.$ $0.02)$. As for dense aggregations, $R$. chacei shrimps were nearly absent from $R$. exoculata nurseries, with only $2 R$. chacei juveniles collected in total.

Two other types of shrimp assemblages observed close to diffuse vent fluid emissions were dominated by $R$. chacei $\left(\chi^{2}=16.5-888.1, \mathrm{p}<0.001\right)$ representing $77.4-99.5 \%$ of all the Rimicaris shrimps collected. These were generally not directly adjacent to the dense aggregations, but clearly separated even if the distance could be as short as a few tens of centimetres. One of these 2 types of assemblages was collected in a hole between rocks at TAG or between Bathymodiolus puteoserpentis mussels at Snake Pit (The Moose edifice). Although individuals were rather densely packed, they were hard to see due to the relatively small size of the assemblages and their 'hidden' localization; these assemblages were there- fore called 'hidden aggregations' of $R$. chacei (Fig. 2C; Fig. S4B). These hidden aggregations clearly exhibited larger proportions of $R$. chacei adults than immatures $\left(\chi^{2}=35.6-60.1, \mathrm{p}<0.001\right)$, with adults representing $71.7 \%$ of all $R$. chacei individuals collected there. The sex ratio of $R$. chacei from these assemblages was strictly equilibrated for the sample collected at TAG $\left(\chi^{2}=0, p=0.99\right)$ but slightly deviated toward females for the one collected at Snake Pit $\left(\chi^{2}=7.45, p=0.006\right)$.

The second type of assemblage dominated by $R$. chacei was observed close to diffuse emissions exiting from cracks at the bottom of vent chimneys or in flat areas of the vent fields (Fig. 2D; Fig. S4C). Contrary to the hidden aggregations, significantly larger proportions of immature individuals were observed in these nurseries of $R$. chacei $\left(\chi^{2}=36.8-868.5, \mathrm{p}<\right.$ 0.001 ), representing at least $96.7 \%$ of all individuals of the species. In general, most of these immature individuals were at an early juvenile stage, with stage A juveniles representing $69.9-82.6 \%$ of all immature individuals. One $R$. chacei nursery from TAG exhibited a larger proportion of $R$. chacei subadults than stage A juveniles. 
A last assemblage type found in areas of moderate fluid influence was observed at TAG in the vicinity of dense aggregations (Fig. 2E; Fig. S4D). These assemblages were characterized by similar proportions of the 2 Rimicaris species $\left(\chi^{2}=2.9, p>0.05\right)$ or only slightly larger proportions of one of the 2 species $\left(\chi^{2}=7.5-7.9, \mathrm{p}<0.05\right)$. Larger proportions of $R$. exoculata adults $\left(\chi^{2}=24-30.1, \mathrm{p}<0.001\right)$ and larger proportions of $R$. chacei immatures $\left(\chi^{2}=56.4-208.9\right.$, $\mathrm{p}<0.001)$ were usually observed in these assemblages. However, in one of these assemblages, similar proportions of adults and immature individuals were found for both species $\left(\chi^{2}=0.4-2.5, p>0.05\right)$. In all of them, most of the immature shrimps were at an advanced juvenile stage for both species, stage A juveniles representing at most 7.3 and $2.4 \%$ of all immature individuals respectively for $R$. exoculata and for $R$. chacei. In general, sex ratios of $R$. exoculata from these assemblages did not significantly deviate from $1: 1\left(\chi^{2}=0.1-3, p>0.05 ; n=2\right)$, except in 1 assemblage with a large bias toward females $\left(\chi^{2}=117.4, \mathrm{p}<0.001\right)$.

Rimicaris shrimps were also collected at the periphery of the vent chimneys, on inactive sulfides away from the vent fluid activity (Fig. 2F; Fig. S4E). These assemblages of scattered individuals exhibited either similar proportions of the 2 Rimicaris species $\left(\chi^{2}=\right.$ $0.1-2, \mathrm{p}>0.05)$ or larger proportions of $R$. exoculata individuals $\left(\chi^{2}=26.4 \mathrm{p}<0.001\right)$. As in dense aggregations, larger proportions of $R$. exoculata adults over immature individuals were observed in all of these assemblages $\left(\chi^{2}=16.2-44.6, \mathrm{p}<0.001\right)$. The sex ratio of $R$. exoculata from these assemblages deviated from $1: 1\left(\chi^{2}=6.4-16.3, \mathrm{p}<0.001\right)$, with a large bias toward males (81.8-93.3\% of all R. exoculata adults). For $R$. chacei, both larger proportion of adults $\left(\chi^{2}=\right.$ 20.2, p < 0.001) and larger proportions of immature individuals $\left(\chi^{2}=28.9, \mathrm{p}<0.001\right)$ were reported in these 2 different population samples. Unlike $R$. exoculata, the sex ratio of $R$. chacei from these assemblages did not significantly deviate from $1: 1\left(\chi^{2}=3, \mathrm{p}=0.11\right)$.

One sample collected from a shrimp assemblage in a flat area with moderate fluid emission away from an active venting chimney at Snake Pit (The Nail edifice), exhibited no clear structure corresponding to one of the 6 assemblages defined above. Rather, it clustered with the hidden aggregations of $R$. chacei adults (Fig. 3). However, unlike samples from hidden aggregations, this population showed similar proportions of both Rimicaris species $\left(\chi^{2}=0.2, \mathrm{p}>0.05\right)$. Moreover, proportions of adults and immature individuals were similar $\left(\chi^{2}=0.1-1.4, \mathrm{p}>0.05\right)$, and sex ratio did not significantly deviate from $1: 1\left(\chi^{2}=\right.$
0.1-0.11, p > 0.05) both for $R$. exoculata and $R$. chacei. This assemblage also differed from the others by being dominated by Mirocaris fortunata (58.9\% of all the shrimps sampled), another co-occurring alvinocaridid at these sites that was sporadically observed in very low proportions in the other samples.

\subsection{Thermal and environmental niches of Rimicaris shrimps and their life stages from TAG and Snake Pit}

Average temperatures around Rimicaris assemblages (i.e. mean of temporal observations at each location) ranged between 3.4 and $22.5^{\circ} \mathrm{C}$, with maximum records reaching up to $38.1^{\circ} \mathrm{C}$ and minimum records down to $3.1^{\circ} \mathrm{C}$. Standard deviations that can be considered as the thermal variability recorded in the assemblages varied from 0.3 to $6.9^{\circ} \mathrm{C}$ (with thermal recordings lasting 3 to 6 min $45 \mathrm{~s}$ ). Regarding the vent fluid chemistry, average $\mathrm{H}_{2} \mathrm{~S}$ concentrations around Rimicaris assemblages were between 0 and $8.5 \mu \mathrm{M}$, with $\mathrm{pH}$ variations between 6.86 and 7.9. It is worth mentioning that total sulfide concentrations were measured onboard on recovered samples and may be underestimated compared with the actual in situ conditions. In situ iron concentrations in Rimicaris assemblages were highly variable, with $\mathrm{Fe}^{2+}$ concentrations between 0 and $239 \mu \mathrm{M}$ and $\mathrm{Fe}_{\text {tot }}$ concentrations between 0 and $316 \mu \mathrm{M}$. As minimal temperatures were strongly correlated with average temperature $\left(\mathrm{r}^{2}=0.97, \mathrm{p}<0.05\right)$, only average temperature (Avg.T), temperature standard deviation (Std.T) and maximum temperature (Max.T) were used in the 2 PCAs. No clear significant correlation was observed between any of the thermal descriptors and the concentrations of the different reduced chemical elements (Pearson correlations, $\mathrm{p}>0.01$ in all cases).

For the thermal niches (Fig. 4A,B; 20 sampling points), most of the variance was explained by the 2 first axes of the PCA representing respectively 93.6 and $5.3 \%$ of the inertia. All 3 temperature metrics were very well represented on the PCA $\left(\sum \cos ^{2}=0.99\right.$, 0.99 and 0.98 for Avg.T, Std.T and Max.T, respectively) and were strongly correlated with the first axis (cor = 0.96, 0.95 and 0.99 for Avg.T, Std.T and Max.T, respectively). Avg.T, Std.T and Max.T almost contributed equally to the construction of the first axis (contribution $=32.7,32.4$ and $34.9 \%$, respectively). Similarly, Avg.T and Std.T also contributed equally to the construction of the second axis (contribution = 46.4 and $53.4 \%$, respectively). 

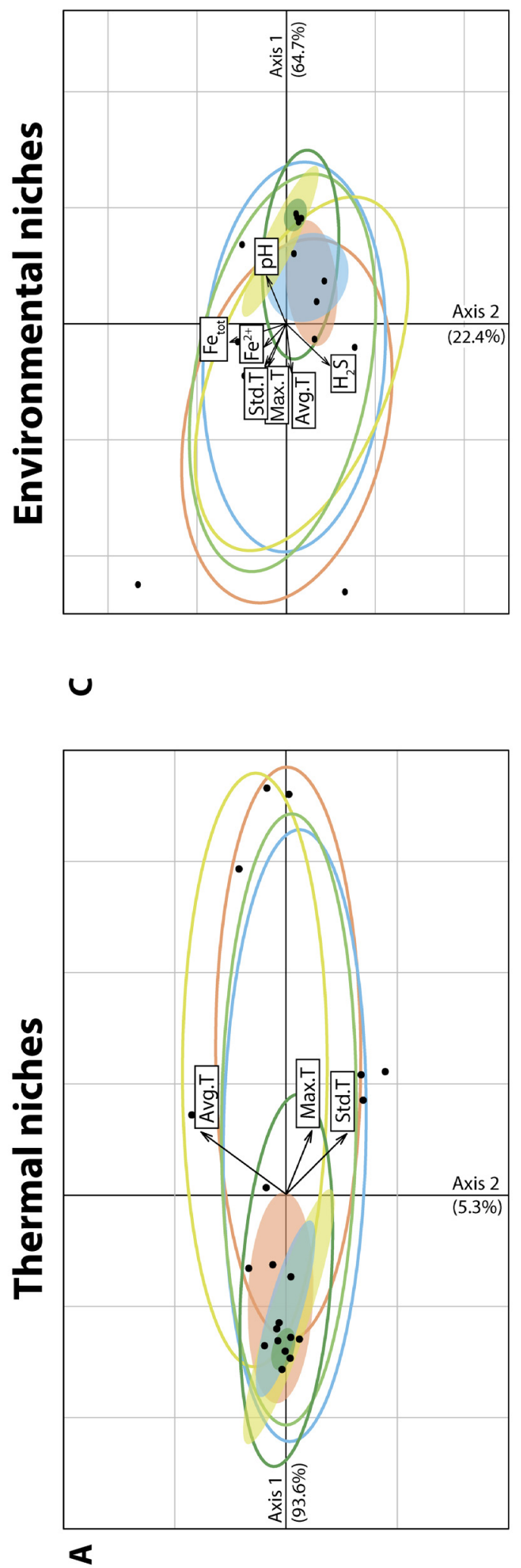

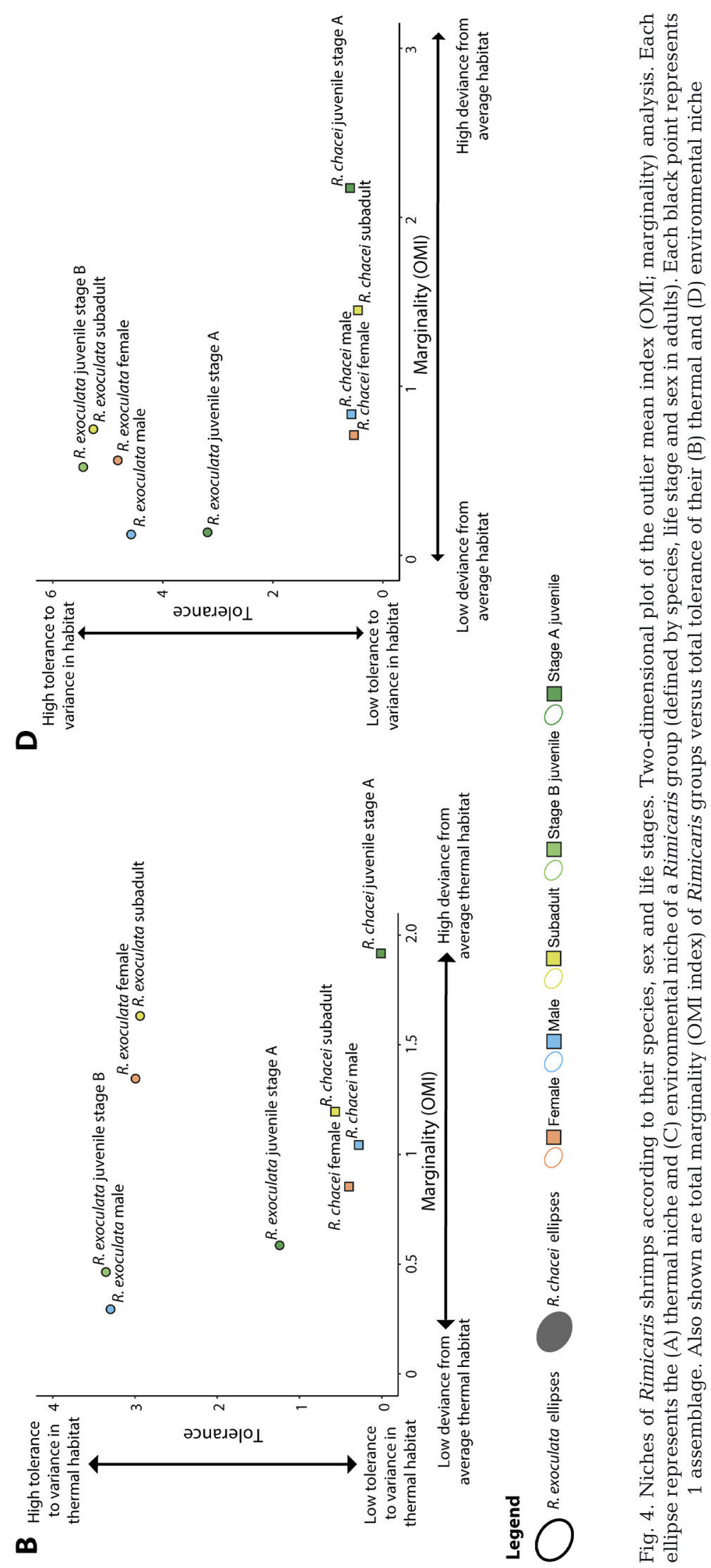


In the case of the environmental niches (Fig. 4C,D; 14 sampling points), a large part of the variance was explained by the 2 first axes of the PCA representing respectively 64.7 and $22.4 \%$ of the inertia. All environmental parameters were relatively well represented on the first 2 axes of the PCA, with $\Sigma \cos ^{2}>0.85$ for all parameters except for Std.T and $\mathrm{pH}\left(\sum \cos ^{2}=0.81\right.$ and 0.70 , respectively). Thermal descriptors as well as pH correlated more with the first axis (cor $=-0.97,-0.88,-0.95$ and 0.83 for Avg.T, Std.T, Max.T and $\mathrm{pH}$, respectively) whereas $\mathrm{H}_{2} \mathrm{~S}$ measurements were more correlated with the second axis (cor $=-0.83$ ). Iron concentrations were equally correlated with the first (cor $=-0.75$ and -0.67 for $\mathrm{Fe}^{2+}$ and $\mathrm{Fe}_{\text {tot }}$ respectively) and the second axes of the PCA (cor $=0.62$ and 0.64 for $\mathrm{Fe}^{2+}$ and $\mathrm{Fe}_{\text {tot }}$ respectively). The thermal descriptors contributed the most to the construction of the first axis (contribution $=21,17$ and 20.1\% for Avg.T, Std.T and Max.T, respectively), followed by $\mathrm{pH}$ and $\mathrm{Fe}^{2+}$ and $\mathrm{Fe}_{\text {tot }}$ (contribution $=15.4,12.5$ and $10 \%$, respectively). On the other hand, $\mathrm{H}_{2} \mathrm{~S}$ contributed in large part to the construction of the second axis followed by iron concentrations (contribution $=24.3$ and $25.8 \%$ respectively for $\mathrm{Fe}^{2+}$ and $\mathrm{Fe}_{\text {tot }}$ ).

As revealed by the OMI analysis, stage A juveniles of $R$. exoculata occupied a distinct thermal niche compared with those of their older counterparts (Fig. 4A), differing both in terms of niche breadth (lower tolerance [Tol] in stage A juveniles) and overall position (Fig. 4B). Although $R$. exoculata adults, subadults and stage B juveniles exhibited similar niche breadths, the mean niche position significantly deviated from the average sampled thermal conditions only for females and subadults (permutation tests: $\mathrm{p}<0.05$, Table 3), suggesting that the distributions of these two were driven by thermal conditions. Overall, the same trends were observed in the OMI analyses with both thermal and chemical descriptors, although significant marginality was only found for $R$. exoculata females $(\mathrm{p}<0.05$; Table 4$)$.

Thermal niches of all $R$. chacei life stages were smaller than those of each $R$. exoculata life stage (Fig. 4A). Stage A juveniles of $R$. chacei displayed a smaller niche breadth as other $R$. chacei life stages, as well as a mean niche position that significantly deviated from the average sampled thermal conditions (Fig. 4B; permutation test, $\mathrm{p}<0.05$ ). Conversely, niche positions of $R$. chacei adults and subadults did not significantly depart from the average sampled thermal conditions (Fig. 4B). Environmental niches of $R$. chacei exhibited the same trends as those observed for thermal niches (Fig. 4C,D, Table 4).

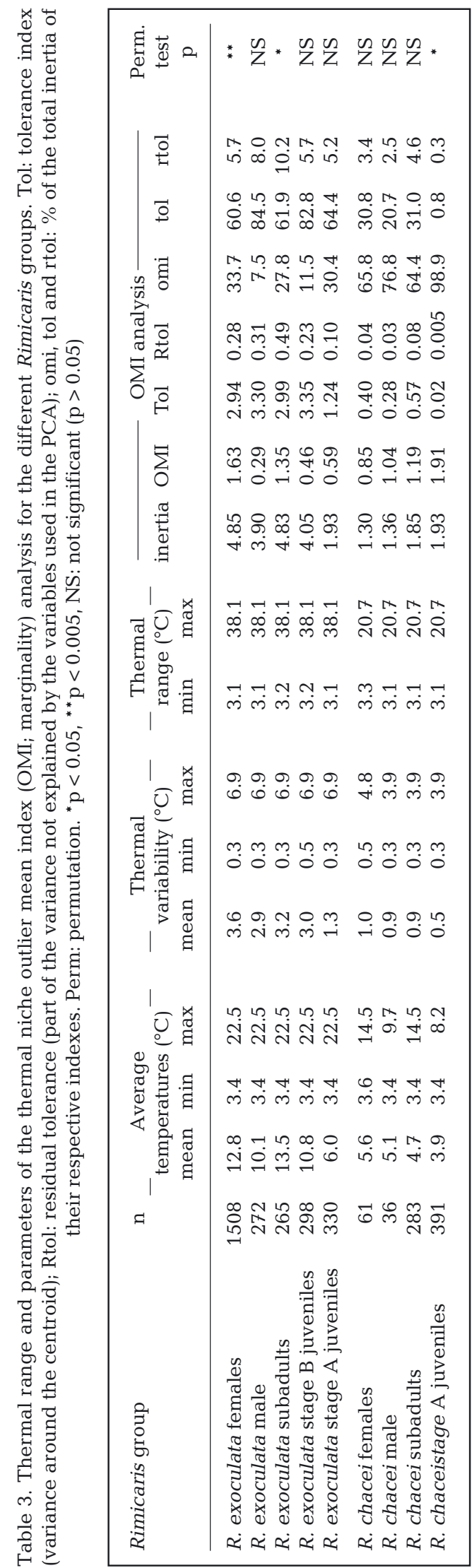




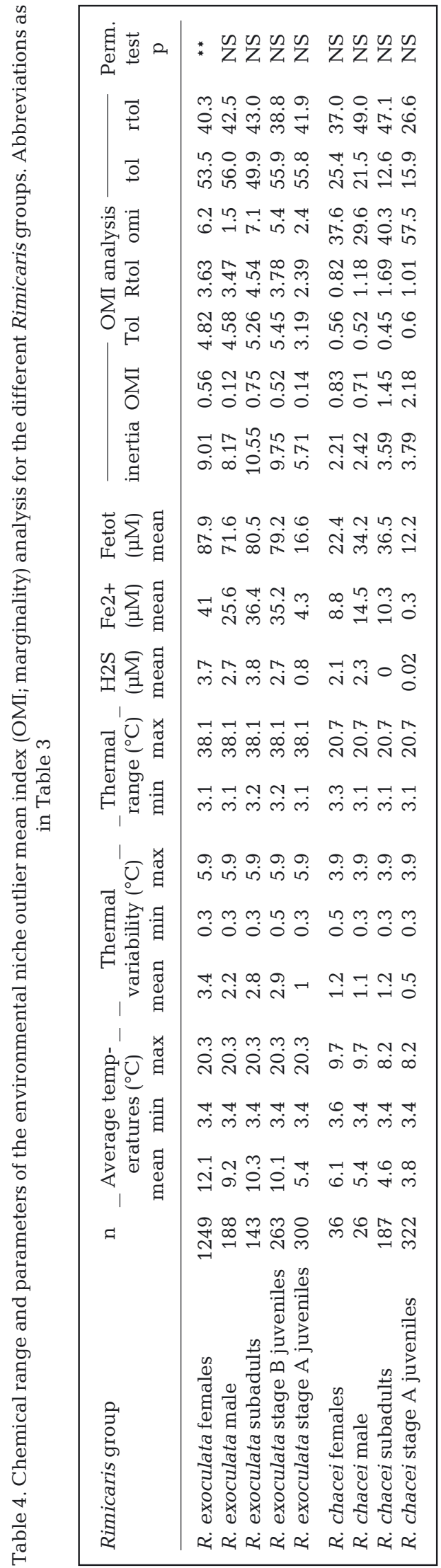

For the thermal niches, residual tolerance (RTol) ranged from 0.3 to $10.2 \%$ of total inertia; thus, the variables used to describe these niches explained $89.8-99.7 \%$ of the niche distribution of the different Rimicaris life stages (Table 3). On the other hand, RTol for the environmental niches ranged from 26.6 to $49 \%$ of total inertia; thus, the variables used to describe these niches only explained $51-74.4 \%$ of the niche distribution of the different Rimicaris life stages (Table 4).

\section{DISCUSSION}

\subsection{Small-scale distribution of Rimicaris life stages along an environmental gradient}

Our temperature measurements indicate that thermal conditions around the different $R$. exoculata assemblages of TAG and Snake Pit ranged between 3.4 and $22.5^{\circ} \mathrm{C}$, with maximal peaks of temperatures up to $38.1^{\circ} \mathrm{C}$ (Table 3 ). These results slightly extend the known thermal range occupied by these shrimps compared with previous in situ temperature measurements in $R$. exoculata aggregations, which reported average thermal conditions between 4.6 and $16^{\circ} \mathrm{C}$, and up to $25^{\circ} \mathrm{C}$ at maximum (Desbruyères et al. 2001, Geret et al. 2002, Zbinden et al. 2004, Schmidt et al. 2008). Although $R$. exoculata experiences $100 \%$ of mortality when exposed for $1 \mathrm{~h}$ to $33^{\circ} \mathrm{C}$ in closed pressurized chambers, these shrimps tolerate shorter exposures of $10 \mathrm{~min}$ at $39^{\circ} \mathrm{C}$ with only $35 \%$ mortality (Ravaux et al. 2019). With a defined critical thermal maximum (CTmax) of $38^{\circ} \mathrm{C}$ for this species, it thus appears that $R$. exoculata occupies most of its fundamental thermal niche in situ. We also noticed important movements of shrimps in aggregations where average temperature exceed $20^{\circ} \mathrm{C}$ (samples PL06A1, PL15A3 and PL20A1) whereas the others tended to remain steady, confirming the in vivo behavioral observations of Ravaux et al. (2019).

In contrast, we observed that $R$. chacei inhabits a narrower thermal niche, between 3.4 and $14.5^{\circ} \mathrm{C}$, up to $20.7^{\circ} \mathrm{C}$ at maximum, regardless of the life stage considered (Table 3 ). In the absence of experimental work on $R$. chacei thermotolerance, it is unclear if their more limited distribution within the hydrothermal vent gradient stems from a physiological limitation or from biological interactions such as competition with its congenerics. This question can be answered in part by a comparison with Mirocaris fortunata, another alvinocaridid shrimp from the MAR, which has a thermal tolerance similar to that of $R$. 
exoculata (Shillito et al. 2006) but occupies a more restricted thermal habitat (Desbruyères et al. 2001, Methou 2019). The narrower distribution of $R$. chacei could also simply be related to a lower thermal preference, as seen in many vent species that preferentially select habitats with cooler temperatures than their upper thermal limit (Bates et al. 2010). This all suggests that temperature per se is not a sufficient limiting factor to explain differences in alvinocaridid shrimp distributions.

Similarly, our dataset also points out that $R$. exoculata inhabits a wider range of reduced compound concentrations (traced through in situ total dissolvable iron) than $R$. chacei for a given life stage, although this trend was much less marked between the earliest juvenile stages of the 2 species. Our in situ chemistry measurements around biological communities indicated significant deviation from the conservative dilution model as has already been reported in previous studies (Le Bris et al. 2006, 2019, Nakamura \& Takai 2014). This deviation from a conservative dilution of the endmember originates from the highly reactive nature of the sulfides and iron species and the consumption or production of these reduced compounds by microbial activity.

At both fields, an important zonation between adults and juvenile stages was also found for $R$. exoculata and for $R$. chacei. This spatial segregation along the thermal gradient is reflected in the distinct thermal niches observed between the earliest juveniles and the other life stages for the 2 Rimicaris species. Similar differences in distribution of bathymodiolin mussel life stages have been hypothesized to be related to intraspecific competition for space between adults and juveniles (Comtet \& Desbruyères 1998, Husson et al. 2017). This was further supported by evidence of recruitment inhibition by high-density assemblages of adult mussels from the East Pacific Rise (Lenihan et al. 2008). Still, an influence of intraspecific competitive interactions among Rimicaris shrimps is tempered by their high motility as well as the non-negligible presence of early juveniles within several high-density assemblages dominated by adult stages. A progressive acquisition of a high thermal tolerance of these recruiting stages, as seen in postlarval stages of the intertidal shrimp Palaemon elegans (Ravaux et al. 2016), could also limit their upper thermal distribution. Additionally, distributions of $R$. exoculata and $R$. chacei juveniles further differ by their habitat topography, i.e. on steep chimney walls for $R$. exoculata nurseries and within flat areas or smooth slopes for $R$. chacei nurseries. As topography strongly influences the overall current hydrodynam- ics, with low-topography areas generally associated with low mixing rates (Girard et al. 2020), these structural differences between habitats might reflect the relative dependency of each species on the vent fluid mixing gradient essential to fuel their ongoing developing symbiosis (Methou et al. 2020). Although our measurements were limited, this variability of the fluid chemistry between nursery habitats of the 2 species could be observed in our dataset with lower $\mathrm{H}_{2} \mathrm{~S}$ and $\mathrm{Fe}$ concentrations in $R$. chacei nurseries compared with $R$. exoculata ones.

We also confirmed the segregation pattern between males and females of $R$. exoculata observed at TAG in January-February 2014 (Hernández-Ávila et al. preprint: https://doi.org/10.1101/2021.06.27.450066) at each of the studied vent fields. Such a pattern was not observed in $R$. chacei, which also exhibited a more equilibrated sex ratio overall, more similar to what has been observed for its sister species $R$. hybisae (Nye et al. 2013).

Despite apparent relative stability evidenced by the maintenance of an assemblage type in the same area over the years, the spatial zonation of the different Rimicaris life stages also seems dynamic with a succession of assemblages in other areas on short temporal scales. During one of our dives at TAG, we witnessed the disappearance of an entire dense aggregation assemblage of $R$. exoculata adults replaced by an aggregate of $R$. chacei hidden between rocks in just about $10 \mathrm{~d}$ (Fig. S5). Unfortunately, we are currently unable to confirm if this succession of assemblages is related to a modification of the environmental conditions, as we could not obtain initial temperature measurements prior to the replacement of the dense aggregate, due to technical difficulties during the dive.

In addition to the assemblages dominated by a particular life stage of one of the 2 Rimicaris species, different types of mixed assemblages were also observed in areas a little further away from the fluids. Interestingly, these assemblages with a mixed proportion of the 2 species were also the assemblages with the lowest densities of Rimicaris individuals, visually countable in contrast to the other more dense assemblage types (Fig. 2). These more peripheral assemblages with less marked structuration could correspond to assemblages with much lower densities due to suboptimal habitat conditions for Rimicaris spp. Lower supply of reduced compounds to feed their cephalothoracic symbionts, or an absence of a symbiont pool to renew their symbiotic communities along their molt cycle, would limit the establishment of these species in these areas. A finer environmental characterization of these particular areas would be 
required to better understand the subtle ecological differences that could exist between these habitats and the denser shrimp assemblage types. In any case, these density-dependent trends suggest that competitive processes might occur between $R$. chacei and $R$. exoculata life stages.

\subsection{Population dynamics of Rimicaris shrimps from the MAR are driven by biotic interactions}

Similar to most species from hydrothermal vents, $R$. exoculata and $R$. chacei exhibited multimodal sizefrequency distributions, suggesting a discontinuous recruitment pattern in both species, thus confirming previous observations made for $R$. exoculata in 2014 (Hernández-Ávila et al. preprint). Still, population structures of the 2 congeneric Rimicaris species from the MAR differed widely with a large post-recruitment collapse of $R$. chacei populations at both vent fields. This collapse was even more pronounced for the TAG population, where immature individuals represented more than $90 \%$ of all the individuals collected. This implies either a high mortality rate of $R$. chacei early post-settlement stages in comparison with $R$. exoculata and/or a large variability in the magnitude of the different larval settlement events. Although temporal tracking of these populations could not be performed, important aggregations of $R$. chacei juveniles in nurseries were reported between January and February 2014 (Hernández-Ávila et al. preprint) as well as between March and April 2017 (Methou et al. 2020). Therefore, it is less likely that the observed variations between $R$. chacei life stages abundance would be related to variations in larval supply and/or settlement success between years.

Therefore, we hypothesize that the post recruitment collapse observed in $R$. chacei populations results more probably from a higher juvenile mortality that could be explained by different, not necessarily mutually exclusive, factors (Fig. 5). Among them, predation could have a major impact on $R$. chacei demography, as it has been recognized as one of the most important causes of juvenile mortalities in shallow-water ecosystems (Gosselin \& Qian 1997). The more peripheral and exposed distribution of $R$. chacei juveniles within the vent fields could expose them to a higher predation pressure by populations of Maractis rimicarivora anemones found in these areas and particularly abundant at TAG (Copley et al. 2007). Indeed, we witnessed a juvenile from the $R$. chacei nursery area being caught by these anemones during a dive at TAG in 2014 (Video S1 at www.int-res.com/ articles/suppl/m684p001_supp/). Predation by these carnivorous anemones on $R$. exoculata adults has also been observed (Van Dover et al. 1997) and was proposed to affect male individuals from the peripheral areas (Hernández-Ávila et al. preprint) which could explain, at least partially, the large sex ratio bias toward females of this species. Additionally, a larger vulnerability to predation by macrourid fishes could also preferentially affect $R$. chacei juveniles. Despite a limited observation time in these areas, we recorded 2 predation events by these fishes within or close to $R$. chacei nursery assemblages during our samplings at TAG, both in 2014 and in 2018 (Video S1). This higher predatory pressure at TAG would also be in agreement with the greater collapse observed in the populations of $R$. chacei at this site compared with those from Snake Pit (Fig. 1). In contrast, the distribution of $R$. exoculata early juveniles, sheltered on the flanks of large chimney structures or within the dense aggregations of $R$. exoculata adults, probably protects them from this high predatory pressure. These shelters for $R$. exoculata juveniles could also arise from the different chemical regime of those aggregations, acting as a possible deterrent from 'nonvent' vagrant predators such as macrourid fishes.

In addition to their distinct spatial distribution, the juvenile stages of both Rimicaris shrimps differed in their average settlement size, i.e. twice as large for $R$. exoculata compared with $R$. chacei (Methou et al. 2020). Numerous studies on marine fishes and shrimps have reported body size as a key factor in the survival of early juveniles, with a lower overall mortality for larger individuals (Meekan et al. 2006, Gagliano \& McCormick 2007, Mace \& Rozas 2018). Thus, survival of Rimicaris juveniles could fit into the 'bigger is better' hypothesis, whether larger body size would provide them a lower vulnerability against predation, a better physiological state and/or a higher competitive ability. As an alternative to high juvenile mortality, important emigration of $R$. chacei juveniles, i.e. secondary migration, to a different location following their initial settlement at the vent fields could also lead to similar patterns in their population structure. Long-term monitoring with video imagery of the areas of Rimicaris nurseries or individual tracking of early-stage shrimps could help to refine our hypotheses and determine more precisely the relative influence of these different factors on their population dynamics.

Interspecific competition for space between the 2 species, already suggested by their spatial segregation patterns, could also have a major influence on their demography. It is commonly accepted that 


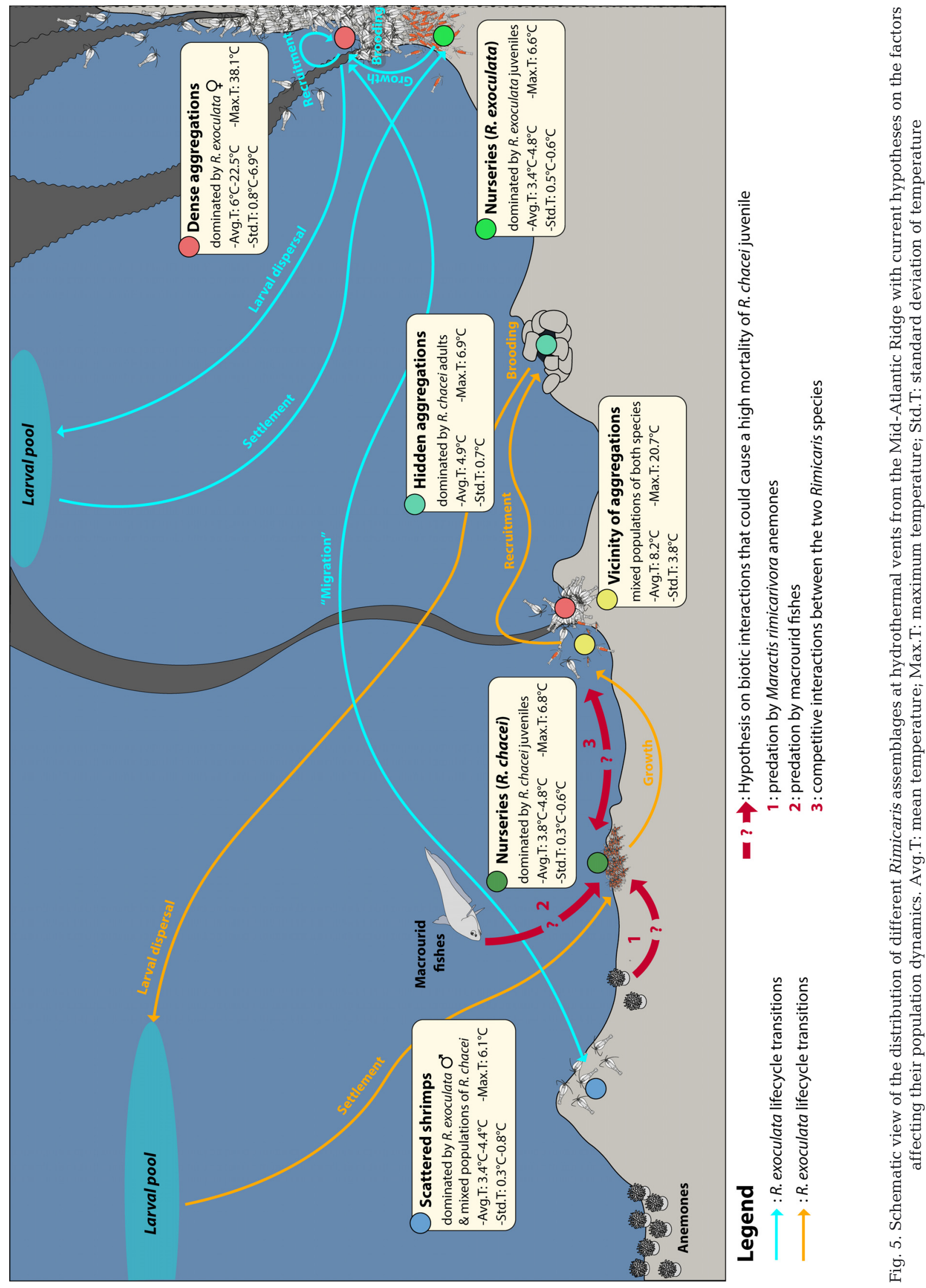


abundant species within an assemblage outcompete less common ones. However, this general statement has been contradicted by various manipulative studies which did not report any effect of being naturally rare or common on the competitive ability of a species (Angel et al. 2006, Matias et al. 2012). Still, marine lobsters can experience important demographic bottlenecks before recruitment, due to the more specific requirements of their early benthic juvenile stages for sheltered areas, which are limited in space (Wahle \& Steneck 1991). In a similar fashion, the low abundance of $R$. chacei adults might result from a lower competitive ability of their early juvenile stages to access areas of active fluid emissions, as suggested by their narrower thermal niche compared with similar stages of $R$. exoculata (Fig. 4).

In hydrothermal vents, competitive processes for space are confounded with competition for food in symbiotrophs whose nutrition depends entirely on their access to the vent fluid reduced elements. Both $R$. exoculata and $R$. chacei are fueled by large communities of filamentous ectosymbionts (Ponsard et al. 2013, Apremont et al. 2018), which progressively make up during their ontogeny an increasing part of their diet after settlement (Methou et al. 2020). A more limited access to areas of active fluids for $R$. chacei juveniles could potentially lead to a limitation to primarily acquire their episymbionts and develop a sufficient nutritive symbiotic community within their cephalothorax, which could thus cause mass mortality in these populations. In this scenario, the mixotrophic behavior of $R$. chacei would be the result of a past competition with $R$. exoculata leading to a trophic niche differentiation in $R$. chacei adults over evolutionary timescales, allowing the stable coexistence of the 2 species in the northern MAR vent fields. Additionally, the more limited local diversity at TAG (Desbruyères et al. 2001), likely related to the absence of Bathymodiolus mussel beds known to house large macrofaunal diversity (Desbruyères et al. 2001, Rybakova \& Galkin 2015), enhances even more the limitation in alternative food resources for $R$. chacei, thus possibly explaining the larger postrecruitment collapse of their population at this site. These shrimps are not the first case of population demographics driven by competitive interactions for food in hydrothermal vent ecosystems. Populations of Paralvinella pandorae from Juan de Fuca Ridge exhibited similar post-settlement collapses when found in sympatry with their congener P. palmiformis, whose isotopic niches largely overlap (Levesque et al. 2003).

This link between nutrition modes and population demographics of these shrimps is also further sup- ported when their population structures are compared with those of $R$. hybisae from the Mid-Cayman Spreading Center. Although COI divergence was initially stated between the latter and $R$. chacei (Nye et al. 2012), probably because of inaccurate species identifications in public genetic databases, these 2 species are indeed so close phylogenetically that they cannot be distinguished on the sole basis of the genetic markers used to date (Vereshchaka et al. 2015). In this way, $R$. hybisae populations from the Mid-Cayman Rise can almost be seen as a case of $R$. chacei allopatry with no known competitors like $R$. exoculata. However, $R$. hybisae size-frequency structures largely differ from those of $R$. chacei and appear to be more similar to those of $R$. exoculata (Nye et al. 2013).

It should be noted that, unlike $R$. exoculata, $R$. chacei adults were more difficult to catch with the suction sampler during our attempts to collect them, as they sometimes escaped the tip of the sampler when we approached them. This escape behavior was not observed for the juvenile specimens of the same species inhabiting the nurseries. It is therefore possible that our dataset might slightly underestimate the exact proportion of $R$. chacei adults in the field. Nonetheless, it is unlikely that this potential underestimation of $R$. chacei adult numbers would overturn the extremely marked population structure observed for this species at both vent fields. Similarly, we believe that the disequilibria in sampling effort between the different assemblage types, with an overrepresentation of the dense aggregations against the other assemblage types, is representative of their higher occurrence within the hydrothermal vent fields. A detailed cartography giving the distribution of these assemblages, with shrimp density estimations, when possible, over the entire vent fields would help to better assess our dataset representativeness and if our sampling strategy could have partially affected our conclusions on the population dynamics of these 2 species. Temporal monitoring of these animals would also be necessary to clarify if their population dynamics could not be affected, at least in part, by long-term cyclicities.

The mechanisms by which $R$. chacei populations maintain a high supply of settlers despite a limited adult number comparatively to $R$. exoculata are still unclear. Larger $R$. chacei populations from yet unknown vent fields in the MAR representing source populations, with TAG and Snake Pit as sink populations, at the metapopulation level or differences in reproductive output between $R$. exoculata and $R$. chacei are possible. Additional work on the repro- 
ductive biology of $R$. chacei will be needed to better understand differences in the life history traits of these species. Further experimental studies on the thermal physiology and tolerance to the vent fluid toxic compounds of both $R$. chacei adults and Rimicaris juvenile stages would also be required to understand if the distribution patterns observed between these different life stages are related to physiological limitations or other biotic factors.

Acknowledgements. We thank the captains and crews of the RV 'Pourquoi pas?' and the HOV 'Nautile' submersible team for their efficiency, as well as the chief scientist and scientific parties of and BICOSE 2 cruise. Further thanks go to Leela Morzina for her help in collecting data on shrimp measurements and identification of their life stages and to Emmanuelle Omnes (Ifremer, LEP) for her help in sorting animal samples on board. The use of the CHEMINI device was possible thanks to the help of Dr. Agathe Laës-Huon (ifremer, LDCM). Maps of the sampling sites were provided by Anne-Sophie Alix and Florian Besson (Ifremer, CTDI). We also thank Lyndsay Clavareau (ifremer, DYNECO) for her help with the niche analysis. This work was supported by the Ifremer REMIMA program and the Region Bretagne ARED funding.

\section{LITERATURE CITED}

Angel A, Branch GM, Wanless RM, Siebert T (2006) Causes of rarity and range restriction of an endangered, endemic limpet, Siphonaria compressa. J Exp Mar Biol Ecol 330: 245-260

* Apremont V, Cambon-Bonavita MA, Cueff-Gauchard V, François D, Pradillon F, Corbari L, Zbinden M (2018) Gill chamber and gut microbial communities of the hydrothermal shrimp Rimicaris chacei Williams and Rona 1986: a possible symbiosis. PLOS ONE 13:e0206084

Bates AE, Lee RW, Tunnicliffe V, Lamare MD (2010) Deepsea hydrothermal vent animals seek cool fluids in a highly variable thermal environment. Nat Commun 1: 14

*Beermann J, Franke HD (2012) Differences in resource utilization and behaviour between coexisting Jassa species (Crustacea, Amphipoda). Mar Biol 159:951-957

Bouchemousse S, Lévêque L, Viard F (2017) Do settlement dynamics influence competitive interactions between an alien tunicate and its native congener? Ecol Evol 7: 200-213

Cline JD (1969) Spectrophotometric determination of hydrogen sulfide in natural waters. Limnol Oceanogr 14: 454-458

Comtet T, Desbruyères D (1998) Population structure and recruitment in mytilid bivalves from the Lucky Strike and Menez Gwen hydrothermal vent fields (37 $17^{\prime} \mathrm{N}$ and $37^{\circ} 50^{\prime} \mathrm{N}$ on the Mid-Atlantic Ridge). Mar Ecol Prog Ser 163:165-177

Copley JTP, Jorgensen PBK, Sohn RA (2007) Assessment of decadal-scale ecological change at a deep Mid-Atlantic hydrothermal vent and reproductive time-series in the shrimp Rimicaris exoculata. J Mar Biol Assoc UK 87: 859-867
Desbruyères D, Biscoito $M$, Caprais JC, Colaço A and others (2001) Variations in deep-sea hydrothermal vent communities on the Mid-Atlantic Ridge near the Azores plateau. Deep Sea Res I Oceanogr Res Pap 48:1325-1346

* Dolédec S, Chessel D, Gimaret-Carpentier C (2000) Niche separation in community analysis: a new method. Ecology 81:2914-2927

* Dray S, Dufour AB (2007) The ade4 package: implementing the duality diagram for ecologists. J Stat Softw 22:1-19

* Faure B, Chevaldonné P, Pradillon F, Thiébaut E, Jollivet D (2007) Spatial and temporal dynamics of reproduction and settlement in the Pompeii worm Alvinella pompejana (Polychaeta: Alvinellidae). Mar Ecol Prog Ser 348: 197-211

F Franke HD, Gutow L, Janke M (2007) Flexible habitat selection and interactive habitat segregation in the marine congeners Idotea baltica and Idotea emarginata (Crustacea, Isopoda). Mar Biol 150:929-939

Gagliano M, McCormick MI (2007) Compensating in the wild: Is flexible growth the key to early juvenile survival? Oikos 116:111-120

* Gebruk AV, Southward EC, Kennedy H, Southward AJ (2000) Food sources, behaviour, and distribution of hydrothermal vent shrimps at the Mid-Atlantic Ridge. J Mar Biol Assoc UK 80:485-499

Gebruk AV, Fabri MC, Briand P, Desbruyeres D (2010) Community dynamics over a decadal scale at Logatchev, $14^{\circ} 45^{\prime} \mathrm{N}$, Mid-Atlantic Ridge. Cah Biol Mar 51:383-388

Geret F, Riso R, Sarradin PM, Caprais JC, Cosson RP (2002) Metal bioaccumulation and storage forms in the shrimp, Rimicaris exoculata, from the Rainbow hydrothermal field (Mid-Atlantic Ridge); preliminary approach to the fluid-organism relationship. Cah Biol Mar 43:43-52

* Girard F, Sarrazin J, Arnaubec A, Cannat M, Sarradin PM, Wheeler B, Matabos M (2020) Currents and topography drive assemblage distribution on an active hydrothermal edifice. Prog Oceanogr 187:102397

Gosselin LA, Qian PY (1997) Juvenile mortality in benthic marine invertebrates. Mar Ecol Prog Ser 146:265-282

* Husson B, Sarradin PM, Zeppilli D, Sarrazin J (2017) Picturing thermal niches and biomass of hydrothermal vent species. Deep Sea Res II Top Stud Oceanogr 137:6-25

Jollivet D, Empis A, Baker MC, Hourdez S, Comtet T, Desbruyères D, Tyler PA (2000) Reproductive biology, sexual dimorphism, and population structure of the deep sea hydrothermal vent scale-worm, Branchipolynoe seepensis (Polychaeta: Polynoidae). J Mar Biol Assoc UK 80:55-68

Jones LA, Ricciardi A (2014) The influence of pre-settlement and early post-settlement processes on the adult distribution and relative dominance of two invasive mussel species. Freshw Biol 59:1086-1100

Kelly NE, Metaxas A (2008) Population structure of two deepsea hydrothermal vent gastropods from the Juan de Fuca Ridge, NE Pacific. Mar Biol 153:457-471

*Komai T, Segonzac M (2008) Taxonomic review of the hydrothermal vent shrimp genera Rimicaris Williams \& Rona and Chorocaris Martin \& Hessler (Crustacea: Decapoda: Caridea: Alvinocarididae). J Shellfish Res 27:21-41

Le Bris N, Sarradin PM, Birot D, Alayse-Danet AM (2000) A new chemical analyzer for in situ measurement of nitrate and total sulfide over hydrothermal vent biological communities. Mar Chem 72:1-15

Le Bris N, Rodier P, Sarradin PM, Le Gall C (2006) Is temperature a good proxy for sulfide in hydrothermal vent habitats? Cah Biol Mar 47:465-470 
Le Bris N, Yücel M, Das A, Sievert SM, LokaBharathi PP, Girguis PR (2019) Hydrothermal energy transfer and organic carbon production at the deep seafloor. Front Mar Sci 5:531

Lenihan HS, Mills SW, Mullineaux LS, Peterson CH, Fisher CR, Micheli F (2008) Biotic interactions at hydrothermal vents: recruitment inhibition by the mussel Bathymodiolus thermophilus. Deep Sea Res I Oceanogr Res Pap 55: 1707-1717

Levesque C, Juniper SK, Marcus J (2003) Food resource partitioning and competition among alvinellid polychaetes of Juan de Fuca Ridge hydrothermal vents. Mar Ecol Prog Ser 246:173-182

Macdonald P, Du J (2012) Mixdist: finite mixture distribution models. R Package version 05-4. http://CRAN.R-project. org $/$ package $=$ mixdist

Mace MM, Rozas LP (2018) Fish predation on juvenile penaeid shrimp: examining relative predator impact and size-selective predation. Estuaries Coasts 41:2128-2134

Marsh L, Copley JT, Tyler PA, Thatje S (2015) In hot and cold water: Differential life-history traits are key to success in contrasting thermal deep-sea environments. J Anim Ecol 84:898-913

Marticorena J, Matabos M, Sarrazin J, Ramirez-Llodra E (2020) Contrasting reproductive biology of two hydrothermal gastropods from the Mid-Atlantic Ridge: implications for resilience of vent communities. Mar Biol 167: 109

Matabos M, Thiebaut E (2010) Reproductive biology of three hydrothermal vent peltospirid gastropods (Nodopelta heminoda, N. subnoda and Peltospira operculata) associated with Pompeii worms on the East Pacific Rise. J Molluscan Stud 76:257-266

Matias MG, Chapman MG, Underwood AJ, O'Connor NE (2012) Increasing density of rare species of intertidal gastropods: tests of competitive ability compared with common species. Mar Ecol Prog Ser 453:107-116

Meekan MG, Vigliola L, Hansen A, Doherty PJ, Halford A, Carleton JH (2006) Bigger is better: size-selective mortality throughout the life history of a fast-growing clupeid, Spratelloides gracilis. Mar Ecol Prog Ser 317: 237-244

Menge BA (1991) Relative importance of recruitment and other causes of variation in rocky intertidal community structure. J Exp Mar Biol Ecol 146:69-100

Methou P (2019) Lifecycles of two hydrothermal vent shrimps from the Mid-Atlantic Ridge: Rimicaris exoculata and Rimicaris chacei. $\mathrm{PhD}$ dissertation, University of Brest

Methou P, Michel LN, Segonzac M, Cambon-Bonavita MA, Pradillon F (2020) Integrative taxonomy revisits the ontogeny and trophic niches of Rimicaris vent shrimps. R Soc Open Sci 7:200837

Mullineaux LS, Metaxas A, Beaulieu SE, Bright M and others (2018) Exploring the ecology of deep-sea hydrothermal vents in a metacommunity framework. Front Mar Sci $5: 49$

KMünzbergová Z (2013) Comparative demography of two cooccurring Linum species with different distribution patterns. Plant Biol 15:963-970

*Nakamura K, Takai K (2014) Theoretical constraints of physical and chemical properties of hydrothermal fluids on variations in chemolithotrophic microbial communities in seafloor hydrothermal systems. Prog Earth Planet Sci 1:5

Nye V, Copley J, Plouviez S (2012) A new species of Rimi- caris (Crustacea: Decapoda: Caridea: Alvinocarididae) from hydrothermal vent fields on the Mid-Cayman Spreading Centre, Caribbean. J Mar Biol Assoc UK 92:1057-1072

Nye V, Copley JT, Tyler PA (2013) Spatial variation in the population structure and reproductive biology of Rimicaris hybisae (Caridea: Alvinocarididae) at hydrothermal vents on the Mid-Cayman Spreading Centre. PLOS ONE 8:e60319

*Plouviez S, Jacobson A, Wu M, Van Dover CL (2015) Characterization of vent fauna at the Mid-Cayman Spreading Center. Deep Sea Res I Oceanogr Res Pap 97:124-133

* Ponsard J, Cambon-Bonavita MA, Zbinden M, Lepoint G and others (2013) Inorganic carbon fixation by chemosynthetic ectosymbionts and nutritional transfers to the hydrothermal vent host-shrimp Rimicaris exoculata. ISME J 7: 96-109

R Core Team (2020) R: a language and environment for statistical computing. R Foundation for Statistical Computing, Vienna

* Ravaux J, Léger N, Rabet N, Fourgous C, Voland G, Zbinden M, Shillito B (2016) Plasticity and acquisition of the thermal tolerance (upper thermal limit and heat shock response) in the intertidal species Palaemon elegans. J Exp Mar Biol Ecol 484:39-45

* Ravaux J, Léger N, Hamel G, Shillito B (2019) Assessing a species thermal tolerance through a multiparameter approach: the case study of the deep-sea hydrothermal vent shrimp Rimicaris exoculata. Cell Stress Chaperones 24:647-659

Rius M, Turon X, Marshall DJ (2009) Non-lethal effects of an invasive species in the marine environment: the importance of early life-history stages. Oecologia 159: 873-882

* Rybakova (Goroslavskaya) E, Galkin S (2015) Hydrothermal assemblages associated with different foundation species on the East Pacific Rise and Mid-Atlantic Ridge, with a special focus on mytilids. Mar Ecol 36:45-61

Sarradin PM, Lannuzel D, Waeles M, Crassous P and others (2008) Dissolved and particulate metals (Fe, Zn, Cu, Cd, $\mathrm{Pb}$ ) in two habitats from an active hydrothermal field on the EPR at $13^{\circ}$ N. Sci Total Environ 392:119-129

Schmidt C, Le Bris N, Gaill F (2008) Interactions of deep-sea vent invertebrates with their environment: the case of Rimicaris exoculata. J Shellfish Res 27:79-90

Segonzac M, de Saint Laurent M, Casanova B (1993) L'enigme du comportement trophique des crevettes Alvinocarididae des sites hydrothermaux de la dorsale medio-atlantique. Cah Biol Mar 34:535-571

* Shank TM, Lutz RA, Vrijenhoek RC (1998) Molecular systematics of shrimp (Decapoda: Bresiliidae) from deepsea hydrothermal vents, I: Enigmatic 'small orange' shrimp from the Mid-Atlantic Ridge are juvenile Rimicaris exoculata. Mol Mar Biol Biotechnol 7:88-96

Fhillito B, Le Bris N, Hourdez SM, Ravaux J and others (2006) Temperature resistance studies on the deep-sea vent shrimp Mirocaris fortunata. J Exp Biol 209:945-955

* Stookey LL (1970) Ferrozine-a new spectrophotometric reagent for iron. Anal Chem 42:779-781

* Tibshirani R, Walther G, Hastie T (2001) Estimating the number of data clusters via the gap statistic. J R Stat Soc B 63:411-423

Van Dover CL, Polz MF, Robinson J, Cavanaugh CM, Kadko DC, Hickey PJ (1997) Predatory anemones at TAG. Bridge Newsl 12:33-34 
Vereshchaka AL, Kulagin DN, Lunina AA (2015) Phylogeny and new classification of hydrothermal vent and seep shrimps of the family Alvinocarididae (Decapoda). PLOS ONE 10:e0129975

Vuillemin R, Le Roux D, Dorval P, Bucas K and others (2009) CHEMINI: a new in situ CHEmical MINIaturized analyzer. Deep Sea Res I Oceanogr Res Pap 56: 1391-1399

Wahle RA, Steneck RS (1991) Recruitment habitats and nursery grounds of the American lobster Homarus americanus: a demographic bottleneck? Mar Ecol Prog Ser 69: 231-243

Watanabe H, Beedessee G (2015) Vent fauna on the Central Indian Ridge. In: Ishibashi J, Okino K, Sunamura M (eds) Subseafloor biosphere linked to hydrothermal systems: TAIGA concept. Springer, Tokyo, p 205-212

Editorial responsibility: Paul Snelgrove, St. John's, Newfoundland and Labrador, Canada Reviewed by: J. Copley and 1 anonymous referee
Werner EE, Gilliam JF (1984) The ontogenetic niche and species interactions in size-structured populations. Annu Rev Ecol Syst 15:393-425

* Zal F, Jollivet D, Chevaldonné P, Desbruyères D (1995) Reproductive biology and population structure of the deep-sea hydrothermal vent worm Paralvinella grasslei (Polychaeta: Alvinellidae) at $13^{\circ} \mathrm{N}$ on the East Pacific Rise. Mar Biol 122:637-648

Zbinden M, Cambon-Bonavita MA (2020) Rimicaris exoculata: biology and ecology of a shrimp from deep-sea hydrothermal vents associated with ectosymbiotic bacteria. Mar Ecol Prog Ser 652:187-222

K Zbinden M, Le Bris N, Gaill F, Compère P (2004) Distribution of bacteria and associated minerals in the gill chamber of the vent shrimp Rimicaris exoculata and related biogeochemical processes. Mar Ecol Prog Ser 284:237-251

Submitted: September 9, 2021

Accepted: December 30, 2021

Proofs received from author(s): February 9, 2022 